\section{9 attiruror}

\section{HOS PITAL P R A C T I E,}

\section{BRITISH AND FOREIGN.}

Nulla autem est alia pro certo noseendi via, nisi quamplurimas et morborum et dissectionum historias, tum aliorum, tum proprias collectas habere, et iater se comparare.-MorgagnI De Sed. et Caus. Morb., lib.iv. Procmium.

\section{ST. MARY'S HOSPITAL.}

CASE OF VENTRAL HERNIA WITH EXTENSIVE GANGRENE OF INTESTINE ; REMOVAL OF GANGRENOUS PART ; DEATH TWENTY-SIX DAYS AFTER OPERATION; NECROPSY.

(Under the care of Mr. WALTER PYE.)

For the following notes we are indebted to Mr. Thornton, the dresser of the case.

M. T_- aged about forty, was admitted at $\$ .30$ P.M. on May 17th, 1879. Her history was as follows. She became ruptured, apparently on both sides, nine years before, in consequence of a fall, but only the rupture on the left side gave her any trouble. It used to come down pretty often, but was easily reduced. She had never worn a truss, and from her description of the tumour, it was not in the position of an inguinal or femoral rupture. On the morning of the day before her admission the rupture came down, and she could not reduce it. She sent for medical assistance, but the gut could not be returned. Violent and persistent vomiting soon came on, and on the afternoon of the following day (17th) she was advised to apply at the hospital. On the evening of the same day, being much worse, she did so.

When seen at 9 P.M. she presented all the constitutional signs of a person with an acute strangulation. Her history was difficult to elucidate, but apparently the bowels had not been moved for four days. On examination, a painful brawny swelling, four inches in diameter, was found in the left iliac region, evidently being neither an inguinal nor a femoral hernia, but lying very much in the position of a femoral one which had forced its way up so as to lie above Poupart's ligament. The physical signs resembled closely those of an abscess in the abdominal walls in this situation.

An incision about four inches and a half long was made over the tumour, and a considerable length of small intestine was found in a gangrenous condition, being tightly strangulated apparently by the edges of an opening in the trausversalis fascia. The structures of the abdominal wall, however, were so altered by inflammatory infiltration and adhesion, that it was difficult to make out the precise anatomical conditions. The whole mass was horribly offensive and quite soft, and easily broke down under the finger. On slightly enlarging the aperture, and drawing the coil of intestine out, the gangrene was seen to cease abruptly, and each end of the intestine behind the strangulation was apparently quite healthy. It was therefore determined to stitch half the circumference of the healthy gut above the gangrene to a similar part of the gut below it, the two portions being in contact at the ventral aperture. When this was done the whole of the gaugrenous portion, about eight inches, was cut away, leaving a large artificial anus, formed hy stitching the healthy intestine to the abdominal walls. When this was done the finger was passed into the intestine upwards and downwards to see that all was clear, and this was followed by a free escape of fxecal matter from the upper end. During the operation the finger had to be passed into the abdominal cavity, but every care was taken to prevent the passage into it of the decomposing fluids about the wound. When the operation was completed the wound was well swabbed out with carbolic acid ( 1 in 20) and dressed with carbolic oil lint. No other antiseptic precautions were taken. The patient was then given one-third of a grain of morphia hypodermically, and pnt to bed. She had a good night and very little pain. Next morning freal matter passed from the upper opening of the gut; the wound looked healthy; temperature $98^{\circ}$; $n o$ signs of peritonitis. Morphia to be continued, one-sixth of a grain three times a day. On the 19 th the temperature was $94^{\circ} 4^{\circ}$; pulse 72 . There was no abdominal tenderness, except that of the abdominal walls over the wound; free fæcal discharge. There had been two or three fluid motions passed per auum since the operation. A pill of one-third of a grain of opium was ordered to be taken twice a day. On the 21 st the temperature was $98^{\circ}$; pulse 97 . There was a constant discharge of fiecal matter of a greenish colour and thin; its passage caused it good deal of pain. There was no pain or tendenness in the belly.

For the next ten days she went on very weil, aud on June 2nd the artificial anus ceased to discharge. She complained of pain and flatus, and sickness came on. Examination of the upper opening of the gut showed that the finger could be passed up with slight force, but that it was rather firmly gripped by the intestinal walls. Temperature $97 . \mathrm{S}^{\circ}$.

On June 3rd fiecal matter was again passed by the wound. The patient felt much relieved, and the sickness ceased. This improvement was maintained till June 6th, when it was noted that she was not so well. Since the previous night there had been constant vomiting (bilious). 'There was no discharge from the gut, and the patient was depressed. From this time to June loth she steadily grew worse; sickness persisted, and there was very little frecal matter passed. The temperature remained low till the morn ing of June 11th, when it suddenly rose to $103^{\circ}$, and signs of peritonitis appeared. In the evening of the same day she died, twenty-six days after the operation.

At the post-mortem examination the hernia was found to be a ventral one, the aperture being placed just above the canal of Nuck. The ileum had been opened about twenty. four inches above the ileo-cocal valve. The abdominal cavity generally was the seat of diffuse subacute peritonitis, and there was a localised purulent collection in the neighbourhood of the artificial anus. The lower intestinal opening was found firmly united to the wound, but the upper one was, as it were, dragged away from the abdominal wall in part of its circumference by a tense band of the mesentery. The gut was also so placed in the wound that the more tense this band became (e.g., through flatus) the more the intestine became twisted on itself, so as to produce an imperfect volvulus.

Remarks by Mr. Pre.-The reasons for removing the gangrenous intestine and stitching the ends together, instead of learing the mass to separate of itself, were the extent and the degree of the gangrene; it seemed that to leave such a large decomposing mass in the wound could not but be the greater danger of the two. Probably the most remarkable feature in the case is the complete absence of constitutional disturbance for the fortnight following the operation. Had the operation been conducted with rigid antiseptic precautions, that would have been held to be the explanation; but this was not the case. And since, in the course of the operations, the fingers, and therefore some of the products of decomposition, were passed into the $a b$ dominal cavity, it is surprising that acute peritonitis did not occur. The cause of her death was made clear enough by the post-mortem examination. It was evidently due to an incomplete volvulus, caused by the mesentery being somewhat stretched by the attachment of the gut to the abdo. minal walls. Further, this volvulus was not sufficient to produce obstruction while the intestines were tolerably empty, but any slight increase of flatus gave enough distension to cause partial obstruction, and this again, working in a vicious circle, produced still greater distension, vomiting, \&c.; and, finally, was sufficient to tear down the adhesions between the intestine and the abdominal walls, and thus to set up fatal peritonitis. Fad the mesentery been but half an inch longer, it seems not improbable that the patient would have recovered; indeed, so well was she at one time that the question of attempting to restore the continuity of the canal was raised.

It seems likely that by manipulation inside the abdominal cavity the condition of the mesentery could have been dis. covered, and the volvulus which it caused averted by adjusting differently the intestinal walls before fastening them to each other and to the abdominal parietes.

\section{GLASGOW ROYAL INFIRMART.}

\section{RLPTLRE OF THE RIGHT KIDNEY, PERINEPHIITIC} ABSCESS ; DEATH.

(Under the care of Dr. CHARTERIS.)

For the following notes we are indebted to Mr. G. W. Till, resident assistant.

Pobert McD_- aged forty-five years, was admitted on June ?th, 18:9, with the following history. He had been : 
healthy, fairly temperate man, with the exception of occasional outbreaks on Saturday nights. On the evening of Saturday, May 24th, a fortnight before admission, he had been indulging freely, and on returning home he tripped and fell, and by doing so his right side came in contact with the corner of a table. About an hour afterwards he was seized with violent vomiting, and there was considerable soreness over the side. This vomiting continued daily after taking food. It occasioned no pain, and he was able to walk about the house without uneasiness. The persistent nature of the vomiting however, alarmed him, and it was in consequence of this he applied at the infirmary.

The patient was observed to be thin and careworn, and expressed great anxiety to be free from vomiting and subsequent thirst. Some of the vomited matter was seen in a vessel. It was of a yellowish-green colour, fluid consistence, and in appearance was not unlike that seen after a prolonged alcoholic debauch, when the stomach refuses everything. A careful examination was made, and no pain was experienced on pressure over any part of the body, nor was there any sign of discolouration at the supposed seat of injury. The respiratory and cardiac systems were found to be healthy, and on examination of the urine both with heat and nitric acid, no trace of albumen was observed then or afterwards, neither was any sediment detected. Its colour was orange-yellow, sp. gr. 1018. His temperature on the day of admission was $100^{\circ}$, but it fell on the second day to $98 \cdot 6^{\circ}$, and so continued.

The patient lingered for sixteen days, gradually becoming weaker and more exhausted by constant retching, whether food was taken or not. He complained of no pain, and obtained some sleep at nights. Ice, effervescing draughts, hypodermic injection of morphia, in no way alleviated the chief, and, in fact, his only, symptom-vomiting, though temporary relief was experienced by a pill containing creasote and opium. During the last two days of his illness hiccup supervened, and prevented sleep. In the end he died, thirty days after the injury, without delirium or coma, and was able to thank nurses and others for their care and attention.

The obscurity attendant on the case during life was solved by the post-mortem examination made by Dr. Foulis two days afterwards. Dr. Foulis's report is as follows :-

Necropsy, thirty-six hours after death.-Lungs contain minute miliary tubercles, more especially the right, being present only in one small patch near the apex of the left lung. The right pleura is everywhere adherent to the walls of the thorax. On opening the abdomen, the omentum, mesentery, and other parts of the peritoneum have an extremely dark-purple colour, apparently the result of ecchymosis into the subperitoneal tissue. The peritoneum covering the right kidney bulges out considerably, pushing forwards and to one side the small intestines; and on opening into the swelling the peritoneum is found to be very much thickened. Between the kidney and the peritoneal covering, and extending around the kidney, there is an abscess which contains about sixteen ounces of a peculiar, bloodtinged purulent fluid. The right kidney itself is rather large, weighing seven ounces and a half, and is ruptured completely but very irregularly along its transverse diameter, rather below the centre, the upper fragment having attached the ureter and renal vessels. This upper fragment is paler and more friable than normal, and the capsule is easily torn off, leaving a smooth surface. The lower fragment has an extremely dark and congested appearance, the capsule of this portion being in places separated from the cortex by extravasated blood. Both fragments readily tear, and break down under very slight force being used. The renal vessels appear uninjured, but the ureter is very much dilated, and completely filled with a large quantity of white purulent fluid, very much thicker in consistence than that contained within the abscess itself. The pus in the ureter does not extend below the brim of the true pelvis, the pas sage being impervious to pus from that point outwards. The left kidney is large, weighing seven ounces, and on section appears white and anæemic, the cortical portion being rather thickened, and the capsule readily torn off, leaving a smooth pale surface. The stomach was very much dilated, and contained a small quantity of greenish-yellow, soursmelling fluid. The brain very large, weighing fifty-nine ounces, but otherwise uormal. All the other organs of the ljody were perfectly healthy.

Remarlis by Dr. CharTERIS.-There are many points of interest in this case, perhaps the most remarkable of which was the obscurity, or rather the absence of any symptoms during life to arouse the least suspicion as to the nature of the case, or to assist in the diagnosis. Other points were the normal condition of the temperature throughout, the absence of pain and swelling in the lumbar region, considering the extent and quantity of pus-formation. Another interesting fact was the normal condition of the urine throughout his illness.

Dr. Dunlop, one of my colleagues at Anderson's College and the Royal Infirmary, has furnished me with the following notes of cases of ruptured kidney, which have been observed by him in the exercise of his duties as one of the medico-legal examiners for Lanarkshire. The publication of these may form a fitting sequel to the case.

THREE CASES OF RUPTURED KIDNEY,

Which had been made the subject of Post-mortem Examina. tion by direction of the Crown.

The first case was that of a man, aged twenty-nine years, who was found lying dead in Glasgow-green. From the position in which the body was found and the circumstances connected with the death as subsequently ascertained, it was concluded that the deceased while in a state of intoxication may have been thrown with some violence against an iron railing, over which he was ultimately pitched, and thereafter rolled down the embankment. As he was seen alive at a late hour at night and on the Green, and as his body was found about five or six hours afterwards with rigor mortis well marked, there was a strong probability that the deceased did not live long, possibly not more than two hours after the injury had been inflicted. With the exception of some bruising about the face and scratching of the hands, which may have been received in the fall or in rolling down the bank, there were no marks of violence observed. On laying open the cavity of the abdomen there was found a large quantity of blood, fluid and clotted. On the removal of the blood the right kidney was seen to be flattened and very much lacerated throughout its entire extent, the rents in its structure being numerous and deep. There was blood also extravasated in the tissue behind the peritoneum. There was no blood in the urine in the bladder, and there was no injury to the liver or other organs within the abdominal cavity. The lungs were pale and bloodless. Death had taken place from shock and hæmorrhage.

The second case was that of a boy, aged six years, who was struck on the side by a sack of flour. He had been following closely a cart loaded with flour, when one of the sacks fell off the cart, and in its descent the corner of a sack struck the boy on his left side, knocking him down. On the sack being removed from the prostrate boy, he was carried home, where he lay very pale and suffering much from shock. He only lived two hours. The left kidney was lacerated, but the pieces were not entirely separate, though they were much flattened and torn. There was blood effused in large quantity both behind and in front of the peritoneum. There was no other organ injured.

The third case was different from the other two, in that he survived for sixty hours after the injuries had been received. The patient was a man of forty years of age, who had been in a street row, and had been violently kicked upon the side. After the infliction of the injury, though suffering very much from pain in his side, he walked to his home, a distance of about a mile. There was blood in his urine. His sufferings were very great. Not only were the pains deep in his belly corresponding with the situation of the kidney, but soon there appeared to be set up symptoms of general peritonitis. There was evidence of bruising on the left side, and, in addition to extravasation of blood, there was a brasion of the skin. On post-mortem examination there was found, in the abdomen, much serous fluid, in addition to large clots of blood, and there was evidence of acute peritonitis. The left kidney was torn almost completely through at the hilum, and some urine had been escaping.

Dublin Hospital SUnday Fund.-The total sum obtained by the collections made last November for this purpose has now been published, and amounts to $£ 431918$ s., which includes not only the sums collected in the various churches, but also some special donations not contributed through places of worship. The total obtained in the previous year amounted to $£ 423210 \mathrm{~s}$. 11 d. , so that an increase of $f 877 \mathrm{~s}$. $1 \mathrm{~d}$. has on the last occasion been received, when compared with that of 1878 . 